\title{
Transcription and Qualitative Methods: Implications for Third Sector Research
}

\author{
Caitlin McMullin ${ }^{1}$
}

Accepted: 18 August 2021/Published online: 10 September 2021

(C) International Society for Third-Sector Research 2021

\begin{abstract}
While there is a vast literature that considers the collection and analysis of qualitative data, there has been limited attention to audio transcription as part of this process. In this paper, I address this gap by discussing the main considerations, challenges and implications of audio transcription for qualitative research on the third sector. I present a framework for conducting audio transcription for researchers and transcribers, as well as recommendations for writing up transcription in qualitative research articles.
\end{abstract}

Keywords Qualitative methods · Transcription

\section{Introduction}

The field of third sector studies is inherently interdisciplinary, with studies from political science, management, sociology and social work, among others. Within the field of research, a large percentage (between 40-80\%) of studies employ qualitative methods such as interviews, focus groups and ethnographic observations (von Schnurbein et al., 2018). In order to ensure rigor, qualitative researchers devote considerable time to developing interview guides, consent forms and coding frameworks. While there is a vast literature that considers the collection and the analysis of qualitative data, there has been comparatively limited attention paid to audio transcription, which is the conversion of recorded audio material into a written form that can be analyzed. Despite advances made in

Caitlin McMullin

cnmm@dps.aau.dk

1 Department of Politics \& Society, Aalborg University, Aalborg, Denmark qualitative methodologies and increasing attention to positionality, subjectivity and reliability in qualitative data analysis, the transcription of interviews and focus groups is often presented uncritically as a direct conversion of recorded audio to text. As technology to facilitate transcription improves, many researchers have shifted to using voice-to-text software and companies that employ AI rather than human transcription. These technological advances in transcription, along with shifts in the way that research is undertaken (for example, increasingly via video conferencing as a result of the COVID-19 pandemic), mean that the need to critically reflect upon the place of transcription in third sector research is more urgent.

In this article, I explore the place of transcription in qualitative research, with a focus on the importance of this process for third sector researchers. The article is structured as follows. First, I review the qualitative methods literature on audio transcription and the key themes that arise. Next, I report on a review undertaken of recent qualitative research articles in Voluntas and the way that authors discuss transcription in these articles. Finally, I propose a framework for qualitative third sector researchers to include transcription as part of their research design and elements to consider in including descriptions of the transcription process in writing up qualitative research.

\section{Audio Transcription: What We Know}

At a basic level, transcription refers to the transformation of recorded audio (usually spoken word) into a written form that can be used to analyze a particular phenomenon or event (Duranti, 2006). For many qualitative researchers, transcription has become a fairly taken-for-granted aspect of the research process. In this section, I review the 
methods literature on the process of audio (and video) transcription as part of qualitative research on the third sector, focusing on three key areas-how transcription is undertaken, epistemological and ethical considerations, and the role of technology.

\section{Qualitative research and transcription}

While quantitative research seeks to explain, generalize and predict patterns through the analysis of variables, qualitative research questions are more interested in understanding and interpreting the socially constructed world around us (Bryman, 2016). This means that data are collected through documents, observation and interviews, and the latter are often recorded in order to analyze these as documents. For third sector research, recordings are most commonly made of interviews and focus groups, but may also be of meetings, events and other activities to ensure that researchers do not have to rely on their power of recall or scribbled notes.

Transcription is a notoriously time-consuming and often tedious task which can take between three hours and over eight hours to transcribe one hour of audio, depending on typing speed. Transcription is not, however, a mechanical process where the written document becomes an objective record of the event-indeed, written text varies from the spoken word in terms of syntax, word choice and accepted grammar (Davidson, 2009). The transcriber therefore has to make subjective decisions throughout about what to include (or not), whether to correct mistakes and edit grammar and repetitions. This has been described as a spectrum between "naturalized" transcription (or "intelligent verbatim") which adapts the oral to written norms, and "denaturalized" transcription ("full verbatim"), where everything is left in, including utterances, mistakes, repetitions and all grammatical errors (Bucholtz, 2000).

While some contend that denaturalized transcription is more 'accurate', the same can equally be argued for naturalized, as it allows the transcriber to omit occasions when, for instance, an individual mis-speaks and corrects themselves, thereby allowing the transcriber to record closer to what was intended and how the interviewee might have portrayed themselves in a written form. As Lapadat (2000, p. 206) explains, "Spoken language is structured and accomplished differently than written text, so when talk is re-presented as written text, it is not surprising that readers draw on their knowledge of written language to evaluate it." Other nonverbal cues, such as laughter, tone of voice (e.g. sarcasm, frustration, emphasis) and the use or omission of punctuation, can also drastically alter the meaning or intention of what an individual says. In addition, the transcriber must make decisions about how much contextual information to include, such as interruptions, crosstalk and inaudible segments (Lapadat, 2000). Because of the range of types of research that employ qualitative methods, there is no single set of rules for transcription but rather these decisions must be based on the research questions and approach.

\section{Epistemological and Ethical Considerations}

Because the researcher (or external transcriber) must make these decisions as they translate audio into written text, transcription is an inherently interpretative and political act, influenced by the transcriber's own assumptions and biases (Jaffe, 2007). Every choice that the transcriber makes therefore shapes how the research participant is portrayed and determines what knowledge or information is relevant and valuable and what is not. Indeed, two transcribers may hear differently and select relevant spoken material differently (Stelma \& Cameron, 2007). As Davidson (2009) notes (and as I explore in further detail in the next section), despite being a highly interpretive process, transcription is frequently depicted using positivist norms of knowledge creation.

Transcription also involves potential ethical considerations and dilemmas. When working with disadvantaged communities, deciding how to depict research participants in written text can highlight the challenges of ethical representation. As Kvale (1996, pp. 172-3) notes, "Be mindful that the publication of incoherent and repetitive verbatim interview transcripts may involve an unethical stigmatization of specific persons or groups of people". Oliver et al. (2005) similarly demonstrate how transcribers must make decisions about how to represent participants' use of slang, colloquialisms and accents in ways that are accurate but also respectful of the respondent's intended meaning. Some researchers decide to send finished transcriptions to interviewees for approval in order to honor commitments to fully informed consent, to ensure transcription accuracy or in some cases as a means to address the balance of power between the researcher and interviewee. As Mero-Jaffe (2011) describes, on the one hand, this may empower interviewees to control the way that they are portrayed in the research. On the other hand, Mero-Jaffe found that seeking transcript approval from interviewees sometimes increased their embarrassment at the way that their statements appear in text. This may be especially problematic with full verbatim transcriptions.

\section{Technology and Transcription}

As technology improves and AI becomes increasingly able to create written text from recorded audio, researchers might ask-is human transcription even necessary? New options in Computer Assisted Qualitative Data Analysis 
Software (CAQDAS) such as NVivo, Atlas.ti and MAXQDA give qualitative researchers the option to forgo audio-to-text transcription altogether, and instead engage in live coding of audio or video files. Using this method, researchers first watch or listen to recordings to code for nonverbal cues, followed by a stage of note taking and coding based on pre-defined themes and matching these with time codes and nonverbal cues. Finally, researchers then transcribe specific quotes of interest from the recording (Parameswaran et al., 2020). This process may improve immersion in the data and allow researchers to account for dynamics that are often lost in complete audioto-text transcription, such as group interactions and nonverbal communication.

There is a considerable need to develop the evidence base on the role of AI in transcription for qualitative research, with many important publications that consider the issue (e.g. Gibbs et al., 2002; Markle et al., 2011) outof-date given the swift rate of change in AI technologies. Over the last few years, voice and speech recognition technologies have improved dramatically and may now be able to provide researchers with "good enough" first drafts of transcripts (Bokhove \& Downey, 2018), providing certain conditions are in place (e.g. limited number of speakers and excellent audio quality). Using these technologies can save researchers time and money. As a result of the COVID-19 pandemic, many qualitative researchers are now undertaking interviews over Zoom or other video conferencing apps, which is a trend that may continue beyond the pandemic (Dodds \& Hess, 2020). Zoom offers AI live transcription options, which benefits from the generally clear audio quality of a video conference, compared to in-person interviews where there is a greater chance of audio interference and background noise that may be undetected in the moment.

While AI may offer a cheaper and quicker alternative to human transcription, these transcripts will need to be meticulously checked by the researcher to ensure accuracy, fill in missing details or edit for context and readability. Using cloud-based AI transcription services also raises potential ethical concerns about data protection and confidentiality (Da Silva, 2021). There are numerous subjective decisions made in the course of creating a transcription that $\mathrm{AI}$ is unable to process, such as where to include punctuation, which words to include or exclude (such as filler words, hesitations, etc.) and how to denote things such as interruptions, hesitations and nonverbal cues. Voice-to-text software is also generally less accurate in discerning multiple voices or different accents (Bokhove \& Downey, 2018). Several studies have considered how researchers/transcribers can use voice recognition software to listen and repeat the spoken text of an interview into software as a shortcut to traditional typing transcription
(Matheson, 2007; Tilley, 2003), but the above shortcomings and cautions apply.

\section{Transcription and Third Sector Research}

Transcription matters for third sector research because qualitative research methodologies make up a large percentage of studies undertaken on nonprofits-as much as 40-80\% of research published in this field (Igalla et al., 2019; Laurett \& Ferreira, 2018; von Schnurbein et al., 2018). Audio transcription is particularly important for third sector research for several reasons. In conducting qualitative research (which aims to produce rich, rigorous description) and as third sector researchers (who study organizations that seek to improve society and who may be working with traditionally disenfranchised or disadvantaged communities), we have a particular ethical obligation to ensure that our research provides an accurate depiction of our participants' lives and the organizations with which they are involved.

However, transcription is perhaps the most underacknowledged aspect of the qualitative research process, and this is also evident in the way that transcription is discussed in research articles. In order to survey the current depiction of the transcription process in third sector research, I undertook a review of the 212 most recent papers in Voluntas that include the word 'interview' to explore how qualitative research articles discuss transcription as part of their methodology. ${ }^{1}$ Of these papers, 79 were deemed not applicable (because they were quantitative research papers that mentioned interviews in another context, or used the word interview to denote the administering of a structured questionnaire, or systematic review papers reporting on other research). This left 133 articles which were analyzed to explore the extent to which transcription was described-if at all-as part of the research methodology. ${ }^{2}$

The analysis (illustrated in Fig. 1) found that $41 \%$ of papers employing interviews as a research method did not mention transcription at all, while $11 \%$ mentioned transcripts but not the process of transcription. It was not clear from these whether or not interviews were recorded or if researchers relied upon written notes taken during interviews, or how information from the oral interview was converted into analyzable text. The most common discussion of transcription (19\%) was a simple sentence along the lines of "interviews were recorded and transcribed", while

\footnotetext{
1 While this approach may have obscured other methods that employ transcription, such as focus groups, the intention of the survey is to provide a snapshot illustration of transcription and qualitative methods rather than a systematic review.

2 Articles reviewed are listed in Appendix 1.
} 


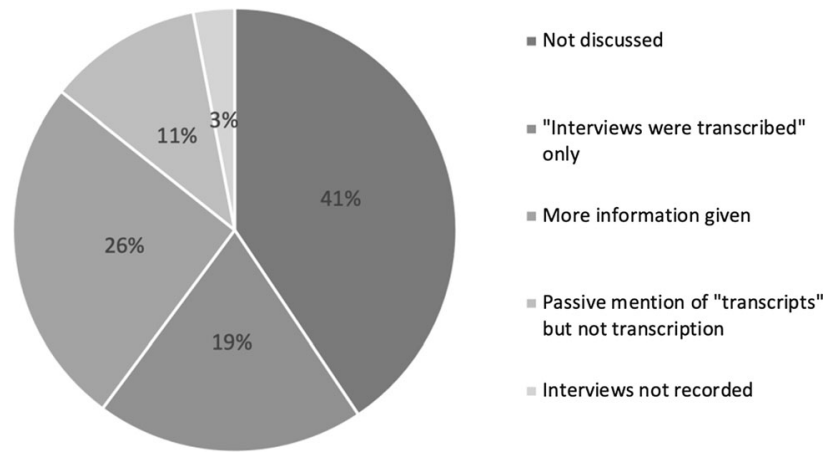

Fig. 1 Transcription in Voluntas qualitative articles

26\% gave some further information including who undertook the transcription (the researcher(s), a research assistant or a commercial company) or that the interviews were transcribed 'verbatim' (with none explaining what they mean by this term). These findings are not dissimilar to a study of qualitative research in nursing, where it was found that $66 \%$ of articles reporting solely that interviews were transcribed, and the remaining articles indicated only "full" or "verbatim" to clarify the process (Wellard \& McKenna, 2001). I also surveyed the first authors' departmental affiliations/field of study to gauge any differences between academic fields (Table 1) although there were not considerable differences.

The fact that over half of the Voluntas articles using interviews as a research method make no mention of the transcription process is a problem for transparency in qualitative research. This tendency may be a symptom of the fact that qualitative researchers face greater challenges in academic publishing that disadvantage longer from, indepth qualitative research to fit within prescribed word limits (Moravcsik, 2014). In researchers' efforts to ensure that qualitative research meets requirements for transparency, rigor and reliability, efforts are concentrated on descriptions of case and participant selection and data analysis while transcription as the conduit between data collection and analysis remains unproblematized. This emphasis reflects the growing influence of positivist views of validity. Ignoring the subjective decisions and theoretical perspectives that determine the creation of a transcript therefore inadvertently presupposes a positivist stance on the objective nature of data which is inconsistent with qualitative methodologies.

\section{A Framework for Undertaking and Reporting on Transcription}

As shown in the previous section, there is currently widespread neglect of transcription as part of interpretive qualitative research on the third sector. In this section, I present key elements for third sector researchers to consider in regard to transcription, both to ensure rigor as part of the qualitative research process and in writing up qualitative research, drawing upon examples of good practice from previous research in Voluntas. These recommendations are based on a review of the literature as well as my personal experience as a qualitative researcher, qualitative methods teacher, and professional transcriber.

\section{Before Transcribing: Ethics and Data Management}

All decisions regarding research design, data collection and data management should be made at the beginning of a qualitative research project when applying for ethical/IRB approval from one's university, and this includes transcription. At this stage, the researcher should confirm with their university whether they have a budget for transcription. Undertaking ethical qualitative research means ensuring standards of transparency, informed consent, confidentiality and protection of the data obtained from the research (Blaxter et al., 2001). Increasing concerns about data protection and legislation such as GDPR in the European Union have prompted many universities to institute strict rules about where research data can be stored. Some universities do not allow the use of certain cloud servers, such as Dropbox. These considerations should be taken into account when deciding how to undertake and record interviews (Da Silva, 2021)-for instance, if you are recording using your mobile phone, it is important to be sure you know whether recordings automatically upload to the cloud. For this reason, it may be preferable to use a traditional digital recorder so you can manually download the files to your computer and know exactly where everything is saved.

\section{Before Transcribing: The Interview}

Before transcription can even be considered, researchers must ensure that they have a suitable audio recording, which begins with the interview itself-whenever possible, interviews should be conducted in a quiet environment without background noise or interruptions and the audio recording device should be placed close enough to the respondent to pick up their voice clearly. While recording interviews with a mobile phone has become increasingly common and easy, using a backup recording device is 
Table 1 Description of transcription and field of first authors

\begin{tabular}{|c|c|c|c|c|}
\hline Field & $\begin{array}{l}\text { Transcription not discussed or } \\
\text { passive mention of transcripts }\end{array}$ & $\begin{array}{l}\text { Discussion of } \\
\text { transcription }\end{array}$ & $\begin{array}{l}\text { Interviews } \\
\text { not recorded }\end{array}$ & Total \\
\hline \multirow[t]{2}{*}{ Business, management \& economics } & 13 & 17 & 1 & \multirow[t]{2}{*}{31} \\
\hline & $42 \%$ & $55 \%$ & $3 \%$ & \\
\hline \multirow[t]{2}{*}{ Political science and international development } & 18 & 8 & 0 & \multirow[t]{2}{*}{26} \\
\hline & $69 \%$ & $31 \%$ & & \\
\hline \multirow[t]{2}{*}{ Sociology } & 8 & 12 & 0 & \multirow[t]{2}{*}{20} \\
\hline & $40 \%$ & $60 \%$ & & \\
\hline \multirow[t]{2}{*}{ Public policy \& public administration } & 12 & 6 & 0 & \multirow[t]{2}{*}{18} \\
\hline & $67 \%$ & $33 \%$ & & \\
\hline \multirow[t]{2}{*}{ Social work } & 4 & 7 & 1 & \multirow[t]{2}{*}{12} \\
\hline & $33 \%$ & $58 \%$ & $8 \%$ & \\
\hline \multirow[t]{2}{*}{ Other or field unclear } & 14 & 10 & 2 & \multirow[t]{2}{*}{26} \\
\hline & $54 \%$ & $38 \%$ & $8 \%$ & \\
\hline \multirow[t]{2}{*}{ Total } & 69 & 60 & 4 & \multirow[t]{2}{*}{133} \\
\hline & $52 \%$ & $45 \%$ & $3 \%$ & \\
\hline
\end{tabular}

always a good idea to mitigate against flat batteries, full memory cards, and human error. If recording with your mobile phone, it's also critical to remember to place it on airplane mode/'do not disturb' for the duration of the interview.

\section{To Transcribe or Not to Transcribe?}

While transcription from audio recordings is considered standard practice in qualitative research (Tracy, 2019), it is not the only way of undertaking qualitative interviews, and it is important to note that there are many reasons why it may not be desirable, appropriate or possible to record interviews at all. In relation to third sector research, this is most commonly the case in community-based research, research with political elites or research in challenging environments. One article explained that they did not record interviews because: "In sectors marked by fear, intimidation, and strong security apparatuses, recording devices would almost certainly have led to self-censorship and limited our access." (Atia \& Herrold, 2018, p. 1046). Similarly, researchers may be unable to record in community settings because of sub-optimal recording conditions (e.g. meeting outside, noisy environments, etc.) or because using recording device makes participants uncomfortable or reinforces power relations between the researcher and participants (Quintanilha et al., 2015).

If researchers decide not to comprehensively transcribe recordings, or decide not to record qualitative fieldwork at all, this should be noted and explained in relation to methods. Other methods of notetaking and analysis may be more suited to certain types of ethnographic research, such as reflexive journaling (Halcomb \& Davidson, 2006), or
Systematic and Reflexive Interviewing and Reporting-a process by which a researcher and research assistant jointly interview participants and write their own reports that include observations and analyses, which are collaboratively analyzed (Loubere, 2017).

\section{How to Transcribe?}

Traditionally, transcribers used foot pedals to play, rewind and fast forward tape recordings while they typed. Now that audio files are digital, several free and low cost programs are available (such as Express Scribe and oTranscribe) that let transcribers set up hot keys to perform the same actions without having to navigate away from their transcript document.

The degree of detail to include in transcripts should be decided upon before interviews are transcribed. This is important because previous research has demonstrated that the format selected for transcription significantly impacts how the researcher interprets the data (Mishler, 2003; Packer, 2017). There is no one best or "most accurate" style of transcription, but rather, a researcher should consider the particular theoretical background and research questions of the study in order to determine where on the scale of full verbatim to intelligent verbatim is most appropriate for the study. Because third sector research is most commonly associated with social science and business disciplines rather than linguistics, it will rarely be necessary or appropriate to employ the conventions of conversation analysis or extreme levels of denaturalized transcription (Bucholtz, 2000). Indeed, it might most frequently be appropriate to employ a version of naturalized/ intelligent verbatim, so that any participants' quotes 
included in written works are more 'readable' and do not include excessive repetitions or verbal fillers such as 'um'.

If the researcher determines that naturalized or intelligent verbatim transcription is the most appropriate for their study, several considerations should be heeded in order to ensure that meaning is not distorted or lost. First, indications of laughter, nonverbal cues (such as sighs, huffs, finger-snaps, sobbing or even blowing raspberries) should be included if these convey important meaning. Other considerations of how to transcribe may be based more on personal preference and the ability to produce a document that is easily analyzable in the researcher's chosen medium. For instance, wide margins on one side can be useful for researchers who choose to analyze their data on paper or in Microsoft Word, while other more flowing templates will work better to import into software such as NVivo. It can also be useful to include time stamps for unclear or inaudible statements, or at regular intervals (e.g. every minute) which makes it much easier to check a transcript against the original audio.

\section{Who Transcribes?}

As discussed in the consideration of qualitative studies, the prevalence of the passive voice when reporting on transcription (i.e. "interviews were transcribed") obscures the important distinction of who undertook the transcription. If the researcher transcribes recordings themselves, then it is generally acceptable to assume the coherence between the research approach and approach to transcription, as well as the researcher's confidence that the written transcript is an accurate record of the event/interview that took place. If, however, the researchers choose to outsource transcription to a research assistant or commercial transcription company, then care should be taken to give detailed and thorough instructions about the elements described above. The researcher should also spot check transcripts for accuracy, fill in any missed words/inaudibles and ensure that the transcription document fulfils their expectations in regard to level of verbatim, style and formatting.

Ideally, transcribers should be hired who have specialist knowledge of the subject matter and familiarity with the accents or dialect of the speakers. They should be provided with a key information about the project, such as the research questions, important terms and acronyms. Lapadat (2000) provides several useful suggestions when hiring transcribers in order to ensure transcription quality and increase rigor. First, rather than fully outsourcing transcription, the researchers can transcribe some interviews or portions of interviews themselves in order to provide an example for transcribers and develop a transcription protocol. Another option when employing research assistants to transcribe interviews is to include them directly in the interviews (either as a co-interviewer or observer), so they have direct involvement in the research and context.

Finally, when working with external transcribers it can also be valuable to encourage transcribers to keep memos of the transcription process or contextual observations and impressions that may not come through in the written text. For instance, does the interviewee sound tired, frustrated, distracted or nervous? Does the interviewer interrupt the respondent frequently (which the transcriber may choose to edit for readability)? Or did the interview take place somewhere public, like a cafe, which may have made the respondent more guarded? Such information is often lost, particularly in projects that involve multiple research team members (for instance, a PI, multiple interviewers, research assistants and/or professional transcribers).

\section{Writing about Transcription}

Due to limited space or word limits, it is not typically possible or desirable to include all of the above details in research articles. Instead, at a minimum, researchers should include who transcribed the audio recordings as part of a commitment to ethical and transparent qualitative research. If this was done by anyone other than the researchers, authors should ideally describe the measures taken to ensure accuracy (developing a protocol for transcribers, spot checking, proofreading, sending transcripts to interviewees if appropriate) and ethical considerations (such as data protection and confidentiality).

Second, researchers should indicate the type of transcription-whether selective (pulling out relevant quotes and themes, or transcribing just the 'gist'), intelligent verbatim/naturalized or full verbatim/denaturalized. The choice of type of transcription should align to the researcher's epistemological position and theoretical framework.

Finally, researchers should include any other subjective decision-making that took place during the transcription process, in much the same way that researchers are encouraged to be transparent about their subjectivity and positionality in undertaking interviews and analysis of qualitative data (McCorkel \& Myers, 2003). This may include information about selecting the level of verbatim, working with external transcribers, feedback from interviewees on transcripts or efforts to ensure accuracy of transcripts and coherence with the research approach.

The following quotes provide good examples of how to write about transcription:

The interviews, which were conducted in the native language of the interviewees by six female HebrewArabic-speaking interviewers, were recorded, translated, and transcribed verbatim. [...] Immediately following the interview, each interviewer transcribed 
and translated her interviews into Hebrew. In this manner, we sought to achieve a translation that was as close as possible to the interviewer's insights regarding the participants, and we regarded the interviewers as active agents in the creation of knowledge. (Yanay-Ventura et al., 2020, p. 6)

Three Spanish speaking investigators transcribed all of the interviews from audio recording devices, checked each other's transcription for accuracy, and analyzed the interviews using thematic analysis (Braun \& Clarke, 2006). The transcribers observed the focus groups and took notes on participants' voices and other identifying traits to help the transcription process go more smoothly. Researchers aided the transcribers in this regard by asking participants at the beginning of the focus groups to introduce themselves using a pseudonym and briefly remark upon how they preferred to spend their time. (Schwingel et al., 2017, p. 170)

In both of these examples, the authors treat the process of transcription as part of the broader research process, rather than as an automatic conversion of audio to text. While there is limited clarification about the type of transcription (beyond 'verbatim'), the discussion of the subjective decision-making as part of the transcription process and acknowledgment of the agency of the individuals undertaking transcription increases transparency and therefore rigor.

\section{Conclusions}

Qualitative research can help us to understand some of the important issues impacting the third sector in ways that quantitative methods fall short of explaining, such as the ways that individuals and organizations make sense of public policy and societal challenges, how and why organizations design their services and activities in particular ways, and the intricacies of the relationships between boards, executives, staff and volunteers. Qualitative methods training stresses that an interpretivist epistemological position sees knowledge as socially constructed, yet transcription has slipped through the cracks of methodological examination in the process of creating and interpreting meaning.

In this short article, I sought to draw our attention to this important stage of qualitative data collection and analysis and call on third sector researchers to critically reflect upon transcription both in conducting research and in writing about it. I have focused primarily on the transcription of interviews, rather than focus groups or other multi-person events. All of the points raised in my framework transcription apply to these methods of data collection as well; however, there are further issues that need to be taken into consideration regarding focus groups that warrant further attention, such as the issues of power and accuracy of transcription when there are multiple people speaking and interrupting one another. Researchers employing multi-person recordings should therefore devote more time and consideration to transcription. Finally, technology continues to advance in the area of voice recognition, which may save researchers considerable time and/or money in transcription; however, I implore scholars to see transcription through an interpretivist rather than positivist lens, to ensure that the production of written transcripts is not approached as the creation of objective knowledge.

\section{Appendix 1: Articles Reviewed}

Aasland, A., Kropp, S., \& Meylakhs, A. Y. (2020). Between Collaboration and Subordination: State and Non-state Actors in Russian Anti-drug Policy. Voluntas, 31(2), 422-436. https://doi.org/10.1007/s11266-01900158-9

Åberg, P., Einarsson, S., \& Reuter, M. (2021). Think Tanks: New Organizational Actors in a Changing Swedish Civil Society. Voluntas, 32(3), 634-648. https://doi.org/10.1007/s11266-019-00174-9

Afkhami, A., Nasr Isfahani, A., Abzari, M., \& Teimouri, H. (2019). Toward a Deep Insight into Employee Participation in Employer-Supported Volunteering in Iranian Organizations: A Grounded Theory. Voluntas, 30(5), 1036-1053. https://doi.org/10.1007/s11266-01900141-4

Anasti, T. (2020). The Strategic Action Field of Sex Work and Sex Trafficking: A Case Study of a Contentious Field in Chicago. Voluntas, 31(1), 169-183. https://doi.org/10.1007/s11266-019-00161-0

Appe, S. (2018). Directions in a Post-aid World? SouthSouth Development Cooperation and CSOs in Latin America. Voluntas, 29(2), 271-283. https://doi.org/10. 1007/s11266-017-9838-0

Arhin, A. A., Kumi, E., \& Adam, M.-A. S. (2018). Facing the Bullet? Non-Governmental Organisations' (NGOs') Responses to the Changing Aid Landscape in Ghana. Voluntas, 29(2), 348-360. https://doi.org/10. 1007/s11266-018-9966-1

Arvidson, M. (2018). Change and Tensions in Non-profit Organizations: Beyond the Isomorphism Trajectory. Voluntas, 29(5), 898-910. https://doi.org/10.1007/ s11266-018-0021-z

Atia, M., \& Herrold, C. E. (2018). Governing Through Patronage: The Rise of NGOs and the Fall of Civil 
Society in Palestine and Morocco. Voluntas, 29(5), 1044-1054. https://doi.org/10.1007/s11266-018-9953-6 Ávila, L., \& Amorim, M. (2021). Organisational Identity of Social Enterprises: A Taxonomic Approach. Voluntas, 32(1), 13-27. https://doi.org/10.1007/s11266-02000264-z

Baillie Smith, M., Fadel, B., O'Loghlen, A., \& Hazeldine, S. (2020). Volunteering Hierarchies in the Global South: Remuneration and Livelihoods. Voluntas. https://doi.org/10.1007/s11266-020-00254-1

Bandini, F., Gigli, S., \& Mariani, L. (2021). Social Enterprises and Public Value: A Multiple-Case Study Assessment. Voluntas, 32(1), 61-77. https://doi.org/10. 1007/s11266-020-00285-8

Bano, M. (2019). Partnerships and the Good-Governance Agenda: Improving Service Delivery Through StateNGO Collaborations. Voluntas, 30(6), 1270-1283. https://doi.org/10.1007/s11266-017-9937-y

Barinaga, E. (2020). Coopted! Mission Drift in a Social Venture Engaged in a Cross-Sectoral Partnership. Voluntas, 31(2), 437-449. https://doi.org/10.1007/s11266018-0019-6

Bayalieva-Jailobaeva, K. (2018). New Donor Strategies: Implications for NGOs in Post-Soviet Kyrgyzstan. Voluntas, 29(2), 284-295. https://doi.org/10.1007/ s11266-017-9878-5

Beaton, E. E. (2021). No Margin, No Mission: How Practitioners Justify Nonprofit Managerialization. Voluntas, 32(3), 695-708. https://doi.org/10.1007/s11266019-00189-2

Bergfeld, A., Plagmann, C., \& Lutz, E. (2021). Know Your Counterparts: The Importance of Wording for Stakeholder Communication in Social Franchise Enterprises. Voluntas, 32(1), 104-119. https://doi.org/10. 1007/s11266-020-00289-4

Bidet, E., Eum, H., \& Ryu, J. (2018). Diversity of Social Enterprise Models in South Korea. Voluntas, 29(6), 1261-1273. https://doi.org/10.1007/s11266-018-9951-8

Bies, A., \& Kennedy, S. (2019). The State and the State of the Art on Philanthropy in China. Voluntas, 30(4), 619-633. https://doi.org/10.1007/s11266-019-00142-3

Bradford, A., Luke, B., \& Furneaux, C. (2020). Exploring Accountability in Social Enterprise: Priorities, Practicalities, and Legitimacy. Voluntas, 31(3), 614-626. https://doi.org/10.1007/s11266-020-00215-8

Cannon, S. M. (2020). Legitimacy as Property and Process: The Case of an Irish LGBT Organization. Voluntas, 31(1), 39-55. https://doi.org/10.1007/s11266019-00091-x

Carlsen, H. B., Doerr, N., \& Toubøl, J. (2020). Inequality in Interaction: Equalising the Helper-Recipient Relationship in the Refugee Solidarity Movement. Voluntas. https://doi.org/10.1007/s11266-020-00268-9
Chatterjee, D., Subramanian, B., \& Hota, P. K. (2020). Professionalization and Hybridization Dynamics of Social Enterprises. Voluntas, 31(3), 457-471. https:// doi.org/10.1007/s11266-020-00217-6

Chatzichristos, G., \& Nagopoulos, N. (2020). Social Entrepreneurship and Institutional Sustainability: Insights from an Embedded Social Enterprise. Voluntas, 31(3), 484-493. https://doi.org/10.1007/s11266-01900188-3

Chaves-Avila, R., \& Savall-Morera, T. (2019). The Social Economy in a Context of Austerity Policies: The Tension Between Political Discourse and Implemented Policies in Spain. Voluntas, 30(3), 487-498. https://doi. org/10.1007/s11266-018-00075-3

Chewinski, M. (2019). Coordinating Action: NGOs and Grassroots Groups Challenging Canadian Resource Extraction Abroad. Voluntas, 30(2), 356-368. https:// doi.org/10.1007/s11266-018-0023-x

Clear, A., Paull, M., \& Holloway, D. (2018). Nonprofit Advocacy Tactics: Thinking Inside The Box? Voluntas, 29(4), 857-869. https://doi.org/10.1007/s11266-0179907-4

Clerkin, B., \& Quinn, M. (2019). Restricted Funding: Restricting Development? Voluntas, 30(6), 1348-1364. https://doi.org/10.1007/s11266-018-00048-6

Cookingham Bailey, E. (2020). Advocacy and Service Delivery in the Voluntary Sector: Exploring the History of Voluntary Sector Activities for New Minority and Migrant Groups in East London, 1970s-1990s. Voluntas. https://doi.org/10.1007/s11266-020-00253-2

Crack, A. M. (2018). The Regulation of International NGOS: Assessing the Effectiveness of the INGO Accountability Charter. Voluntas, 29(2), 419-429. https://doi.org/10.1007/s11266-017-9866-9

Crotty, J., \& Ljubownikow, S. (2020). Creating Organisational Strength from Operationalising Restrictions: Welfare Non-profit Organisations in the Russian Federation. Voluntas, 31(6), 1148-1158. https://doi.org/10. 1007/s11266-020-00271-0

Deng, G. (2019). Trends in Overseas Philanthropy by Chinese Foundations. Voluntas, 30(4), 678-691. https:// doi.org/10.1007/s11266-017-9868-7

Dinh, K., Hong, K. T., Haire, B., \& Worth, H. (2021). Historic and Contemporary Influences on HIV Advocacy in Vietnam. Voluntas, 32(3), 610-620. https://doi.org/10. 1007/s11266-020-00220-x

Dong, Q., Guo, J., \& Huang, C.-C. (2019). Nonprofit Alliance in China: Effects of Alliance Process on Goal Achievement. Voluntas, 30(2), 300-311. https://doi.org/ 10.1007/s11266-018-9990-1

Edenfield, A. C., \& Andersson, F. O. (2018). Growing Pains: The Transformative Journey from a Nascent to a 
Formal Not-For-Profit Venture. Voluntas, 29(5), 1033-1043. https://doi.org/10.1007/s11266-017-9936-z Elsayed, Y. (2018). At the Intersection of Social Entrepreneurship and Social Movements: The Case of Egypt and the Arab Spring. Voluntas, 29(4), 819-831. https://doi.org/10.1007/s11266-017-9943-0

Eschweiler, J., Svensson, S., Mocca, E., Cartwright, A., \& Villadsen Nielsen, L. (2019). The Reciprocity Dimension of Solidarity: Insights from Three European Countries. Voluntas, 30(3), 549-561. https://doi.org/10. 1007/s11266-018-0031-x

Eynaud, P., Juan, M., \& Mourey, D. (2018). Participatory Art as a Social Practice of Commoning to Reinvent the Right to the City. Voluntas, 29(4), 621-636. https:// doi.org/10.1007/s11266-018-0006-y

Falkenhain, M. (2020). Dividing Lines: Understanding the Creation and Replication of Fragmentations Among NGOs in Hybrid Regimes. Voluntas, 31(4), 663-673. https://doi.org/10.1007/s11266-019-00185-6

Fang, Q., Fisher, K. R., \& Li, B. (2020). Follower or Challenger? How Chinese Non-governmental Organizations Manage Accountability Requirements from Funders. Voluntas, 31(4), 722-735. https://doi.org/10.1007/ s11266-019-00184-7

Farid, M., \& Li, H. (2021). Reciprocal Engagement and NGO Policy Influence on the Local State in China. Voluntas, 32(3), 597-609. https://doi.org/10.1007/ s11266-020-00288-5

Fehsenfeld, M., \& Levinsen, K. (2019). Taking Care of the Refugees: Exploring Advocacy and Cross-sector Collaboration in Service Provision for Refugees. Voluntas, 30(2), 422-435. https://doi.org/10.1007/s11266-01900097-5

Ferguson, G. (2018). The Social Economy in Bolivia: Indigeneity, Solidarity, and Alternatives to Capitalism. Voluntas, 29(6), 1233-1243. https://doi.org/10.1007/ s11266-018-0013-Z

Fulton, B. R., \& Wood, R. L. (2018). Civil Society Organizations and the Enduring Role of Religion in Promoting Democratic Engagement. Voluntas, 29(5), 1068-1079. https://doi.org/10.1007/s11266-018-9965-2

Gaby, S. (2020). Reconfiguring Organizational Commitments: Boundary Crossing in Civic Groups. Voluntas, 31(6), 1121-1133. https://doi.org/10.1007/s11266-02000272-Z

Gaeta, G. L., Ghinoi, S., Silvestri, F., \& Trasciani, G. (2021). Exploring Networking of Third Sector Organizations: A Case Study Based on the Quartieri Spagnoli Neighborhood in Naples (Italy). Voluntas, 32(4), 750-766. https://doi.org/10.1007/s11266-020-00241-6 García-Orosa, B., \& Pérez-Seijo, S. (2020). The Use of $360^{\circ}$ Video by International Humanitarian Aid Organizations to Spread Social Messages and Increase
Engagement. Voluntas, 31(6), 1311-1329. https://doi. org/10.1007/s11266-020-00280-z

Grazioli, M., \& Caciagli, C. (2018). Resisting to the Neoliberal Urban Fabric: Housing Rights Movements and the Re-appropriation of the 'Right to the City' in Rome, Italy. Voluntas, 29(4), 697-711. https://doi.org/ 10.1007/s11266-018-9977-y

Grubb, A., \& Henriksen, L. S. (2019). On the Changing Civic Landscape in Denmark and its Consequences for Civic Action. Voluntas, 30(1), 62-73. https://doi.org/10. 1007/s11266-018-00054-8

Guha, P. (2019). Going to Scale: A Case Study of an Indian Educational NGO. Voluntas, 30(6), 1365-1379. https://doi.org/10.1007/s11266-019-00099-3

Guo, C., \& Lai, W. (2019). Community Foundations in China: In Search of Identity? Voluntas, 30(4), 647-663. https://doi.org/10.1007/s11266-017-9932-3

Heckert, R., Boumans, J., \& Vliegenthart, R. (2020). How to Nail the Multiple Identities of an Organization? A Content Analysis of Projected Identity. Voluntas, 31(1), 129-141. https://doi.org/10.1007/s11266-01900157-w

Heideman, L. J. (2018). Making Civil Society Sustainable: The Legacy of USAID in Croatia. Voluntas, 29(2), 333-347. https://doi.org/10.1007/s11266-017-9896-3

Hjort, M., \& Beswick, D. (2020). Volunteering and Policy Makers: The Political Uses of the UK Conservative Party's International Development Volunteering Projects. Voluntas. https://doi.org/10.1007/s11266-02000222-9

Holthaus, L. (2019). Furthering Pluralism? The German Foundations in Transitional Tunisia. Voluntas, 30(6), 1284-1296. https://doi.org/10.1007/s11266-018-00074-4 Horvath, A. (2020). The Transformative Potential of Experience: Learning, Group Dynamics, and the Development of Civic Virtue in a Mobile Soup Kitchen. Voluntas, 31(5), 981-994. https://doi.org/10.1007/ s11266-018-00062-8

Horvath, A., Brandtner, C., \& Powell, W. W. (2018). Serve or Conserve: Mission, Strategy, and Multi-Level Nonprofit Change During the Great Recession. Voluntas, 29(5), 976-993. https://doi.org/10.1007/s11266-0179948-8

Huang, Y. (2019). At the Mercy of the State: Health Philanthropy in China. Voluntas, 30(4), 634-646. https:// doi.org/10.1007/s11266-018-9960-7

Ismail, A., \& Johnson, B. (2019). Managing Organizational Paradoxes in Social Enterprises: Case Studies from the MENA Region. Voluntas, 30(3), 516-534. https://doi.org/10.1007/s11266-018-00083-3

Jezierska, K., \& Polanska, D. V. (2018). Social Movements Seen as Radical Political Actors: The Case of the 
Polish Tenants' Movement. Voluntas, 29(4), 683-696. https://doi.org/10.1007/s11266-017-9917-2

Kampen, T., Veldboer, L., \& Kleinhans, R. (2019). The Obligation to Volunteer as Fair Reciprocity? Welfare Recipients' Perceptions of Giving Back to Society. Voluntas, 30(5), 991-1005. https://doi.org/10.1007/ s11266-018-00082-4

Kang, Y. (2019). What Does China's Twin-Pillared NGO Funding Game Entail? Growing Diversity and Increasing Isomorphism. Voluntas, 30(3), 499-515. https://doi.org/10.1007/s11266-018-00085-1

Kappelides, P., Cuskelly, G., \& Hoye, R. (2019). The Influence of Volunteer Recruitment Practices and Expectations on the Development of Volunteers' Psychological Contracts. Voluntas, 30(1), 259-271. https:// doi.org/10.1007/s11266-018-9986-x

Kennedy, D. (2019). The Inherently Contested Nature of Nongovernmental Accountability: The Case of HAP International. Voluntas, 30(6), 1393-1405. https://doi. org/10.1007/s11266-019-00134-3

Kewes, A., \& Munsch, C. (2019). Should I Stay or Should I Go? Engaging and Disengaging Experiences in Welfare-Sector Volunteering. Voluntas, 30(5), 1090-1103. https://doi.org/10.1007/s11266-019-00122-7 Korstenbroek, T., \& Smets, P. (2019). Developing the Potential for Change: Challenging Power Through Social Entrepreneurship in the Netherlands. Voluntas, 30(3), 475-486. https://doi.org/10.1007/s11266-01900107-6

Koubek, M. (2020). When Did They Protest? Beyond Co-optation or Channeling: Effects of EU Funding on Czech Romani NGOs and Civil Society. Voluntas, 31(2), 404-421. https://doi.org/10.1007/s11266-018-0008-9

Kravchenko, Z., \& Moskvina, A. (2018). Entrepreneurial NPOs in Russia: Rationalizing the Mission. Voluntas, 29(5), 962-975. https://doi.org/10.1007/s11266-0180016-9

Kumi, E. (2019). Aid Reduction and NGDOs' Quest for Sustainability in Ghana: Can Philanthropic Institutions Serve as Alternative Resource Mobilisation Routes? Voluntas, 30(6), 1332-1347. https://doi.org/10.1007/ s11266-017-9931-4

Lall, S. A. (2019). From Legitimacy to Learning: How Impact Measurement Perceptions and Practices Evolve in Social Enterprise-Social Finance Organization Relationships. Voluntas, 30(3), 562-577. https://doi.org/10. 1007/s11266-018-00081-5

Lang, R., \& Mullins, D. (2020). Field Emergence in Civil Society: A Theoretical Framework and Its Application to Community-Led Housing Organisations in England. Voluntas, 31(1), 184-200. https://doi.org/10. 1007/s11266-019-00138-z
Laurent, A., Garaudel, P., Schmidt, G., \& Eynaud, P. (2020). Civil Society Meta-organizations and Legitimating Processes: The Case of the Addiction Field in France. Voluntas, 31(1), 19-38. https://doi.org/10.1007/ s11266-019-00094-8

Lee, E. K. M., \& Chandra, Y. (2020). Dynamic and Marketing Capabilities as Predictors of Social Enterprises' Performance. Voluntas, 31(3), 587-600. https:// doi.org/10.1007/s11266-019-00155-y

Li, S. (2020). Global Civil Society Under the New INGO Regulatory Law: A Comparative Case Study on Two INGOs in China. Voluntas, 31(4), 751-761. https://doi. org/10.1007/s11266-019-00101-y

Li, S., \& Wang, X. (2020). Seeking Credibility from Uncertainty: How Formal Cooptation Institution Unleashes Outspoken NGOs. Voluntas, 31(4), 711-721. https://doi.org/10.1007/s11266-020-00204-X

Liu, F., \& Zhang, X. (2020). Who are Volunteers in Urban China? Voluntas. https://doi.org/10.1007/s11266020-00251-4

Lund, V., \& Juujärvi, S. (2018). Residents' Agency Makes a Difference in Volunteering in an Urban Neighbourhood. Voluntas, 29(4), 756-769. https://doi. org/10.1007/s11266-018-9955-4

Marie, B., Isabelle, M., Jordan, B.-L., Hélène, C., Sophie, É., Julie, F., Christine, M., \& Andrée, S. (2020). Promising Practices of Nonprofit Organizations to Respond to the Challenges Faced in Countering the Mistreatment of Older Adults. Voluntas, 31(6), 1359-1370. https://doi.org/10.1007/s11266-020-00252-3 Martinez, D. E., \& Cooper, D. J. (2020). Seeing Through the Logical Framework. Voluntas, 31(6), 1239-1253. https://doi.org/10.1007/s11266-020-00223-8

Mathews, M. A. (2020). The Embeddedness of Nonprofit Leadership in Civic Governance. Voluntas, 31(1), 201-212. https://doi.org/10.1007/s11266-019-00139-y

Mati, J. M. (2020). Civil Society in 'Politics' and 'Development' in African Hybrid Regimes: The Kenyan Case. Voluntas, 31(4), 674-687. https://doi.org/10.1007/ s11266-020-00211-y

Maya-Jariego, I., Holgado-Ramos, D., González-Tinoco, E., Muñoz-Alvis, A., \& Ortega, M. (2020). More Money, More Problems? Resource Dependence and Professionalization of Non-governmental Social Services Organizations in Southern Spain. Voluntas, 31(6), 1212-1225. https://doi.org/10.1007/s11266-020-00256-Z

McLennan, B. J. (2020). Conditions for Effective Coproduction in Community-Led Disaster Risk Management. Voluntas, 31(2), 316-332. https://doi.org/10. 1007/s11266-018-9957-2

McMullin, C., \& Skelcher, C. (2018). The Impact of Societal-Level Institutional Logics on Hybridity: Evidence from Nonprofit Organizations in England and 
France. Voluntas, 29(5), 911-924. https://link.springer. com/article/10.1007/s11266-018-9996-8

Meijs, L., Handy, F., Simons, F.-J., \& Roza, L. (2020). A Social Innovation: Addressing Relative Food Insecurity and Social Exclusion. Voluntas, 31(5), 894-906. https://doi.org/10.1007/s11266-019-00105-8

Meyer, M., \& Simsa, R. (2018). Organizing the Unexpected: How Civil Society Organizations Dealt with the Refugee Crisis. Voluntas, 29(6), 1159-1175. https://doi. org/10.1007/s11266-018-00050-y

Mikołajczak, P. (2020). Social Enterprises' Hybridity in the Concept of Institutional Logics: Evidence from Polish NGOs. Voluntas, 31(3), 472-483. https://doi.org/ 10.1007/s11266-020-00195-9

Milbourn, B., Black, M. H., \& Buchanan, A. (2019). Why People Leave Community Service Organizations: A Mixed Methods Study. Voluntas, 30(1), 272-281. https://doi.org/10.1007/s11266-018-0005-z

Molina, J. L., Valenzuela-García, H., Lubbers, M. J., Escribano, P., \& Lobato, M. M. (2018). "The Cowl Does Make The Monk": Understanding the Emergence of Social Entrepreneurship in Times of Downturn. Voluntas, 29(4), 725-739. https://doi.org/10.1007/s11266-0179921-6

Moraes, R. L., \& Andion, C. (2018). Civil Society and Social Innovation in Public Arenas in Brazil: Trajectory and Experience of the Movement Against Electoral Corruption (MCCE). Voluntas, 29(4), 801-818. https:// doi.org/10.1007/s11266-017-9867-8

Morais-da-Silva, R. L., Segatto, A. P., \& Bezerra-deSousa, I. G. (2020). Connecting Two Sides: A Qualitative Study on Social Innovation Ventures and Poor Communities in an Emerging Economy. Voluntas, 31(5), 966-980. https://doi.org/10.1007/s11266-019-00156-x

Musah-Surugu, I. J., Bawole, J. N., \& Ahenkan, A. (2019). The "Third Sector" and Climate Change Adaptation Governance in Sub-Saharan Africa: Experience from Ghana. Voluntas, 30(2), 312-326. https://doi.org/ 10.1007/s11266-018-9962-5

Mutongwizo, T. (2018). Comparing NGO Resilience and 'Structures of Opportunity' in South Africa and Zimbabwe (2010-2013). Voluntas, 29(2), 373-387. https:// doi.org/10.1007/s11266-017-9881-x

Näslund, H. (2020). Collective Deliberations and Hearts on Fire: Experiential Knowledge Among Entrepreneurs and Organisations in the Mental Health Service User Movement. Voluntas. https://doi.org/10.1007/s11266020-00233-6

Nimu, A. (2018). Surviving Mechanisms and Strategies of Gender Equality NGOs in Romania and Poland. Voluntas, 29(2), 310-332. https://doi.org/10.1007/ s11266-018-9961-6
Noh, J.-E. (2019). Human Rights-Based Child Sponsorship: A Case Study of ActionAid. Voluntas, 30(6), 1420-1432. https://doi.org/10.1007/s11266-018-0010-2

Obaze, Y. (2020). Supply Chain Challenges and Shared Value Destruction in the Community-Based Supply Chain. Voluntas, 31(3), 550-562. https://doi.org/10. 1007/s11266-020-00202-z

Onyx, J., Darcy, S., Grabowski, S., Green, J., \& Maxwell, H. (2018). Researching the Social Impact of Arts and Disability: Applying a New Empirical Tool and Method. Voluntas, 29(3), 574-589. https://doi.org/10. 1007/s11266-018-9968-z

Pape, U., Brandsen, T., Pahl, J. B., Pieliński, B., Baturina, D., Brookes, N., Chaves-Ávila, R., Kendall, J., Matančević, J., Petrella, F., Rentzsch, C., RichezBattesti, N., Savall-Morera, T., Simsa, R., \& Zimmer, A. (2020). Changing Policy Environments in Europe and the Resilience of the Third Sector. Voluntas, 31(1), 238-249. https://doi.org/10.1007/s11266-018-00087-z

Parker, M. A., Mook, L., Kao, C.-Y., \& Murdock, A. (2020). Accountability and Relationship-Definition Among Food Banks Partnerships. Voluntas, 31(5), 923-937. https://doi.org/10.1007/s11266-019-00150-3

Peci, A., Oquendo, M. I., \& Mendonça, P. (2020). Collaboration, (Dis)trust and Control in Brazilian Manufactured Public/Non-profit Partnerships. Voluntas, 31(2), 375-389. https://doi.org/10.1007/s11266-0180027-6

Peralta, K. J., \& Vaitkus, E. (2019). Constructing Action: An Analysis of the Roles of Third Sector Actors During the Implementation of the Dominican Republic's Regularization Plan. Voluntas, 30(6), 1319-1331. https://doi.org/10.1007/s11266-018-0003-1

Pettigrew, S., Jongenelis, M., Jackson, B., \& Newton, R. U. (2019). "Charity Begins at Home": Informal Caring Barriers to Formal Volunteering Among Older People. Voluntas, 30(5), 921-931. https://doi.org/10.1007/ s11266-018-0017-8

Pfeilstetter, R. (2020). Doing Good and Selling Goods. Voluntas, 31(3), 511-520. https://doi.org/10.1007/ s11266-020-00194-w

Pixová, M. (2018). The Empowering Potential of Reformist Urban Activism in Czech Cities. Voluntas, 29(4), 670-682. https://doi.org/10.1007/s11266-0180011-1

Pluciński, P. (2018). Forces of Altermodernization: Urban Social Movements and the New Urban Question in Contemporary Poland. Voluntas, 29(4), 653-669. https://doi.org/10.1007/s11266-018-0007-x

Popplewell, R. (2018). Civil Society, Legitimacy and Political Space: Why Some Organisations are More Vulnerable to Restrictions than Others in Violent and 
Divided Contexts. Voluntas, 29(2), 388-403. https://doi. org/10.1007/s11266-018-9949-2

Puljek-Shank, R. (2018). Civic Agency in Governance: The Role of Legitimacy with Citizens vs. Donors. Voluntas, 29(4), 870-883. https://doi.org/10.1007/ s11266-018-0020-0

Reijnders, M., Schalk, J., \& Steen, T. (2018). Services Wanted? Understanding the Non-take-up of Social Support at the Local Level. Voluntas, 29(6), 1360-1374. https://doi.org/10.1007/s11266-018-00060w

Ruiz Sportmann, A. S., \& Greenspan, I. (2019). Relational Interactions Between Immigrant and Native-Born Volunteers: Trust-Building and Integration or Suspicion and Conflict? Voluntas, 30(5), 932-946. https://doi.org/ 10.1007/s11266-019-00108-5

Sandberg, B., Elliott, E., \& Petchel, S. (2020). Investigating the Marketization of the Nonprofit Sector: A Comparative Case Study of Two Nonprofit Organizations. Voluntas, 31(3), 494-510. https://doi.org/10.1007/ s11266-019-00159-8

Schmid, H., \& Almog-Bar, M. (2020). The Critical Role of the Initial Stages of Cross-Sector Partnerships and Their Implications for Partnerships' Outcomes. Voluntas, 31(2), 286-300. https://doi.org/10.1007/s11266-01900137-0

Sepulveda, L., Lyon, F., \& Vickers, I. (2020). Implementing Democratic Governance and Ownership: The Interplay of Structure and Culture in Public Service Social Enterprises. Voluntas, 31(3), 627-641. https://doi. org/10.1007/s11266-020-00201-0

Shier, M. L., \& Handy, F. (2020). Leadership in Nonprofits: Social Innovations and Blurring Boundaries. Voluntas, 31(2), 333-344. https://doi.org/10.1007/ s11266-018-00078-0

Spencer, S. B., \& Skalaban, I. A. (2018). Organizational Culture in Civic Associations in Russia. Voluntas, 29(5), 1080-1097. https://doi.org/10.1007/s11266-017-9925-2

Stewart, A. J., \& Twumasi, A. (2020). Minding the Gap: An Exploratory Study Applying Theory to Nonprofit Board Management of Executive Transitions. Voluntas, 31(6), 1268-1281. https://doi.org/10.1007/s11266-02000244-3

Stougaard, M. S. (2020). Co-producing Public Welfare Services with Vulnerable Citizens: A Case Study of a Danish-Somali Women's Association Co-producing Crime Prevention with the Local Authorities. Voluntas. https://doi.org/10.1007/s11266-020-00235-4

Strichman, N., Marshood, F., \& Eytan, D. (2018). Exploring the Adaptive Capacities of Shared JewishArab Organizations in Israel. Voluntas, 29(5), 1055-1067. https://doi.org/10.1007/s11266-017-9904-7
Suter, P., \& Gmür, M. (2018). Volunteer Engagement in Housing Co-operatives: Civil Society "en miniature". Voluntas, 29(4), 770-789. https://doi.org/10.1007/ s11266-018-9959-0

Svensson, K., \& Gallo, C. (2018). The Creation of an Unsolicited Organization: Victim Support Sweden. Voluntas, 29(5), 1008-1018. https://doi.org/10.1007/ s11266-018-9978-x

Tadesse, H. A., \& Steen, T. (2019). Exploring the Impact of Political Context on State-Civil Society Relations: Actors' Strategies in a Developmental State. Voluntas, 30(6), 1256-1269. https://doi.org/10.1007/s11266-01800077-1

Taylor, R., Torugsa, N. (Ann), \& Arundel, A. (2020). Organizational Pathways for Social Innovation and Societal Impacts in Disability Nonprofits. Voluntas, 31(5), 995-1012. https://doi.org/10.1007/s11266-01900113-8

Uzcanga, C., \& Oiarzabal, P. J. (2019). Associations of Migrants in Spain: An Enquiry into Their Digital Inclusion in the "Network Society" in the 2010s. Voluntas, 30(5), 947-961. https://doi.org/10.1007/ s11266-019-00162-z

van der Veer, L. (2020). Treacherous Elasticity, Callous Boundaries: Aspiring Volunteer Initiatives in the Field of Refugee Support in Rotterdam. Voluntas. https://doi. org/10.1007/s11266-020-00260-3

van Wessel, M., Naz, F., \& Sahoo, S. (2021). Complementarities in CSO Collaborations: How Working with Diversity Produces Advantages. Voluntas, 32(4), 717-730. https://doi.org/10.1007/s11266-020-00227-4

Vandepitte, E., Vandermoere, F., \& Hustinx, L. (2019). Civil Anarchizing for the Common Good: Culturally Patterned Politics of Legitimacy in the Climate Justice Movement. Voluntas, 30(2), 327-341. https://doi.org/10. 1007/s11266-018-00073-5

Vuković, D. (2018). The Quest for Government Accountability and Rule of Law: Conflicting Strategies of State and Civil Society in Cambodia and Serbia. Voluntas, 29(3), 590-602. https://doi.org/10.1007/ s11266-018-9984-z

Waardenburg, M. (2021). Understanding the Microfoundations of Government-Civil Society Relations. Voluntas, 32(3), 548-560. https://doi.org/10.1007/s11266-02000221-w

Wells, R., \& Anasti, T. (2020). Hybrid Models for Social Change: Legitimacy Among Community-Based Nonprofit Organizations. Voluntas, 31(6), 1134-1147. https://doi.org/10.1007/s11266-019-00126-3

Williamson, A. K., Luke, B., \& Furneaux, C. (2021). Ties That Bind: Public Foundations in Dyadic Partnerships. Voluntas, 32(2), 234-246. https://doi.org/10.1007/ s11266-020-00269-8 
Yanay-Ventura, G. (2019). "Nothing About Us Without Us" in Volunteerism Too: Volunteering Among People with Disabilities. Voluntas, 30(1), 147-163. https://doi. org/10.1007/s11266-018-0026-7

Yanay-Ventura, G., Issaq, L., \& Sharabi, M. (2020). Civic Service and Social Class: The Case of Young Arab Women in Israel. Voluntas. https://doi.org/10.1007/ s11266-020-00210-Z

Zhang, Y., Bradtke, M., \& Halvey, M. (2020). Anxiety and Ambivalence: NGO-Activist Partnership in China's Environmental Protests, 2007-2016. Voluntas, 31(4), 779-792. https://doi.org/10.1007/s11266-020-00237-2

Zihnioğlu, Ö. (2019). The Prospects of Civic Alliance: New Civic Activists Acting Together with Civil Society Organizations. Voluntas, 30(2), 289-299. https://doi.org/ 10.1007/s11266-018-0032-9

Funding No funding was received to assist with the preparation of this manuscript.

\section{Declarations}

Conflict of Interest The author declares that they have no conflict of interest.

\section{References}

Atia, M., \& Herrold, C. E. (2018). Governing through patronage: The rise of NGOs and the fall of civil society in Palestine and Morocco. VOLUNTAS: International Journal of Voluntary and Nonprofit Organizations, 29(5), 1044-1054. https://doi.org/10. 1007/s11266-018-9953-6

Blaxter, L., Hughes, C., \& Tight, M. (2001). How to research (2nd ed.). Open University Press.

Bokhove, C., \& Downey, C. (2018). Automated generation of "good enough" transcripts as a first step to transcription of audiorecorded data. Methodological Innovations, 11(2). https://doi. org/10.1177/2059799118790743.

Braun, V., \& Clarke, V. (2006). Using thematic analysis in psychology. Qualitative Research in Psychology, 3(2), 77-101. https://doi.org/10.1191/1478088706qp063oa.

Bryman, A. (2016). Social research methods (5th ed.). Oxford University Press.

Bucholtz, M. (2000). The politics of transcription. Journal of Pragmatics, 32(10), 1439-1465. https://doi.org/10.1016/S03782166(99)00094-6

Da Silva, J. (2021). Producing 'good enough' automated transcripts securely: Extending Bokhove and Downey (2018) to address security concerns. Methodological Innovations, 14(1), 2059799120987766. https://doi.org/10.1177/2059799120987766

Davidson, C. (2009). Transcription: Imperatives for qualitative research. International Journal of Qualitative Methods, 8(2), $35-52$.

Dodds, S., \& Hess, A. C. (2020). Adapting research methodology during COVID-19: Lessons for transformative service research. Journal of Service Management, 32(2), 203-217. https://doi.org/ 10.1108/JOSM-05-2020-0153
Duranti, A. (2006). Transcripts, like shadows on a wall. Mind, Culture, and Activity, 13(4), 301-310. https://doi.org/10.1207/ s15327884mca1304_3

Gibbs, G. R., Friese, S., \& Mangabeira, W. C. (2002). View of the use of new technology in qualitative research. Orum Qualitative Sozialforschung/Forum: Qualitative Social Research, 3(2). https://www.qualitative-research.net/index.php/fqs/article/view/ $847 / 1840$

Halcomb, E. J., \& Davidson, P. M. (2006). Is verbatim transcription of interview data always necessary? Applied Nursing Research, 19(1), 38-42. https://doi.org/10.1016/j.apnr.2005.06.001

Igalla, M., Edelenbos, J., \& van Meerkerk, I. (2019). Citizens in action, what do they accomplish? A systematic literature review of citizen initiatives, their main characteristics, outcomes, and factors. VOLUNTAS: International Journal of Voluntary and Nonprofit Organizations, 30(5), 1176-1194. https://doi.org/10. 1007/s11266-019-00129-0

Jaffe, A. (2007). Variability in transcription and the complexities of representation, authority and voice. Discourse Studies, 9(6), 831-836. https://doi.org/10.1177/1461445607082584

Kvale, S. (1996). Interviews: An introduction to qualitative research interviewing. Sage.

Lapadat, J. C. (2000). Problematizing transcription: Purpose, paradigm and quality. International Journal of Social Research Methodology, 3(3), 203-219. https://doi.org/10.1080/ 13645570050083698

Laurett, R., \& Ferreira, J. J. (2018). Strategy in nonprofit organisations: A systematic literature review and agenda for future research. VOLUNTAS: International Journal of Voluntary and Nonprofit Organizations, 29(5), 881-897. https://doi.org/10. 1007/s11266-017-9933-2

Loubere, N. (2017). Questioning transcription: The case for the systematic and reflexive interviewing and reporting (SRIR) method. Forum Qualitative Sozialforschung/Forum: Qualitative Social Research, 18(2), Article 2. https://doi.org/10.17169/fqs18.2.2739

Markle, D. T., West, R. E., \& Rich, P. J. (2011). Beyond transcription: Technology, change, and refinement of method. Forum Qualitative Sozialforschung/Forum: Qualitative Social Research, 12(3), Article 3. https://doi.org/10.17169/fqs-12.3. 1564

Matheson, J. L. (2007). The voice transcription technique: Use of voice recognition software to transcribe digital interview data in qualitative research. Qualitative Report, 12(4), 547-560.

McCorkel, J. A., \& Myers, K. (2003). What difference does difference make? Position and privilege in the field. Qualitative Sociology, 26(2), 199-231. https://doi.org/10.1023/A: 1022967012774

Mero-Jaffe, I. (2011). 'Is that what I Said?' Interview transcript approval by participants: An aspect of ethics in qualitative research. International Journal of Qualitative Methods, 10(3), 231-247. https://doi.org/10.1177/160940691101000304

Mishler, E. (2003). Representing discourse: The rhetoric of transcription. In N. Fielding (Ed.), Interviewing. Sage.

Moravcsik, A. (2014). Transparency: The revolution in qualitative research. PS: Political Science \& Politics, 47(1), 48-53. https:// doi.org/10.1017/S1049096513001789

Oliver, D. G., Serovich, J. M., \& Mason, T. L. (2005). Constraints and opportunities with interview transcription: Towards reflection in qualitative research. Social Forces, 84(2), 1273-1289. https:// doi.org/10.1353/sof.2006.0023

Packer, M. J. (2017). The science of qualitative research. Cambridge University Press.

Parameswaran, U. D., Ozawa-Kirk, J. L., \& Latendresse, G. (2020). To live (code) or to not: A new method for coding in qualitative 
research. Qualitative Social Work, 19(4), 630-644. https://doi. org/10.1177/1473325019840394

Quintanilha, M., Mayan, M. J., Thompson, J., \& Bell, R. C. (2015). Different approaches to cross-lingual focus groups: Lessons from a cross-cultural community-based participatory research project in the ENRICH study. International Journal of Qualitative Methods, 14(5), 1609406915621419. https://doi.org/10. $1177 / 1609406915621419$

Schwingel, A., Wiley, A., Teran-Garcia, M., McCaffrey, J., Gálvez, P., Hawn, R., Villegas, E., Coba, S., Vizcarra, M., Luty, G., Montez, R., \& The Abriendo Caminos Promotora Project Group. (2017). More than help? Volunteerism in US Latino culture. VOLUNTAS: International Journal of Voluntary and Nonprofit Organizations, 28(1), 162-183. https://doi.org/10.1007/s11266016-9731-2

Stelma, J. H., \& Cameron, L. J. (2007). Intonation units in spoken interaction: Developing transcription skills. Text \& Talk, 27(3), 361-393. https://doi.org/10.1515/TEXT.2007.015

Tilley, S. A. (2003). "Challenging" research practices: Turning a critical lens on the work of transcription. Qualitative Inquiry, 9(5), 750-773. https://doi.org/10.1177/1077800403255296
Tracy, S. J. (2019). Qualitative research methods: Collecting evidence, crafting analysis (2nd ed.). John Wiley \& Sons.

von Schnurbein, G., Perez, M., \& Gehringer, T. (2018). Nonprofit comparative research: Recent agendas and future trends. VOLUNTAS: International Journal of Voluntary and Nonprofit Organizations, 29(3), 437-453. https://doi.org/10.1007/s11266017-9877-6

Wellard, S., \& McKenna, L. (2001). Turning tapes into text: Issues surrounding the transcription of interviews. Contemporary Nurse, 11(2-3), 180-186. https://doi.org/10.5172/conu.11.2-3. 180

Yanay-Ventura, G., Issaq, L., \& Sharabi, M. (2020). Civic service and social class: The case of young Arab women in Israel. VOLUNTAS: International Journal of Voluntary and Nonprofit Organizations. https://doi.org/10.1007/s11266-020-00210-z

Publisher's Note Springer Nature remains neutral with regard to jurisdictional claims in published maps and institutional affiliations. 